\title{
Isolated bilateral ptosis as the presentation of midbrain tuberculoma
}

Sir,

Isolated nuclear involvement of the oculomotor nerve is uncommon. Typical features of a nuclear third nerve lesion include unilateral third nerve palsy, bilateral superior rectus palsy and bilateral incomplete ptosis. ${ }^{[1]}$ Here, we report a patient with bilateral incomplete ptosis without any other ocular or neurological signs and discuss the clinico-imaging correlation.

A 14-year-old girl presented with headache and bilateral ptosis of two weeks duration. She had no diplopia or other neurological symptoms. On examination, she had bilateral symmetrical ptosis [Figure 1], normal elevation of both eyeballs [Figure 2] and normal pupillary size and reaction. Rest of the neurological examination was normal.

The magnetic resonance imaging (MRI) brain revealed a thick-walled ring-enhancing lesion in the dorsal midbrain in the region of the oculomotor nucleus, possibly affecting the region of the caudal central (levator palpebrae superioris) subnucleus [Figure 3]. Radiological features were suggestive of tuberculoma. She was empirically started on antituberculous treatment and steroids, with which she showed clinical 


\section{improvement.}

Isolated bilateral ptosis has been previously reported in association with midbrain lesions due to subacute encephalitis ${ }^{[2]}$ and midbrain hemorrhage. ${ }^{[3]}$ It should be noted, however, that it is more common to find ptosis in association with upgaze paresis. This is because

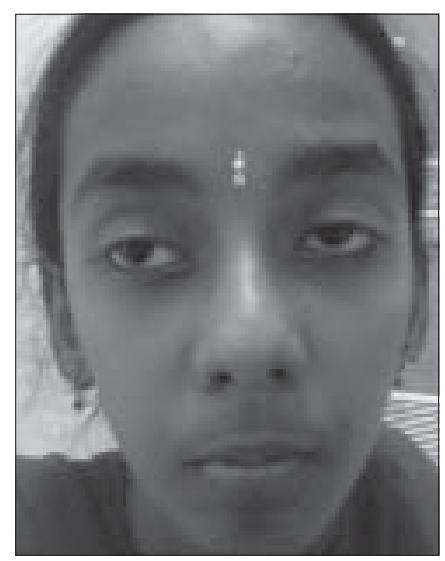

Figure 1: Clinical photograph of the patient showing bilateral incomplete ptosis

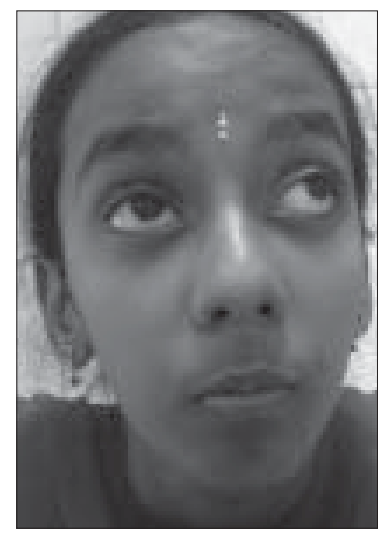

Figure 2: Clinical photograph of the patient showing normal elevation of the eyeballs

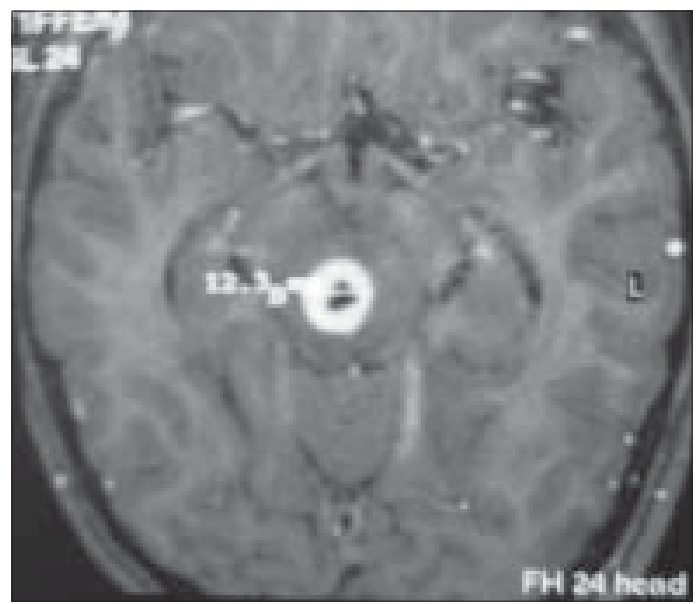

Figure 3: Post-gadolinium MRI axial section through caudal midbrain showing a thick-walled ring-enhancing lesion in the region of caudal central subnucleus the unpaired superior rectus subnuclei are located medially in close association with the caudal central subnucleus (levator palpebrae subnucleus). This case is reported for its unique clinical presentation, which can be explained on the basis of lesion location on MRI. To the best of our knowledge, isolated bilateral ptosis due to midbrain tuberculoma has not been previously reported.

\section{Sudhir Kumar, Garikapati Rajshekher, Subhashini Prabhakar}

Department of Neurological Sciences, Apollo Hospitals, Hyderabad, India. E-mail: drsudhirkumar@yahoo.com

\section{References}

1. The localization of lesions affecting the ocular motor system. In: Brazis PW, Masdeu JC, Biller J. Localization in clinical neurology. $5^{\text {th }}$ ed. Philadelphia: Lippincott Williams and Wilkins; 2007. p. 175-9.

2. Conway VH, Rozdilsky B, Schneider RJ, Sundaram M. Isolated bilateral complete ptosis. Can J Ophthalmol 1983;18:37-40.

3. Chang DB, Lin YY, Guo WY, Wang S, Tsai CP, Lin KP, e al. Midbrain hemorrhage presenting as bilateral ptosis without hemiplegia: A case report. Zhonghua Yi Xue Za Zhi (Taipei) 1995;55:185-8.

Accepted on 12-03-2008 